
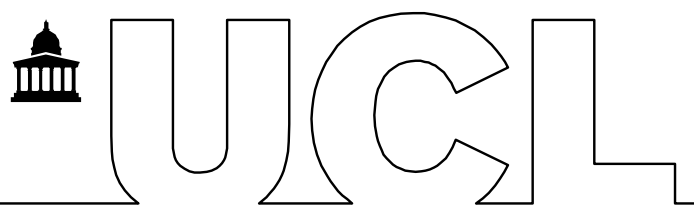

Aguayo, S; Donos, N; Spratt, D; Bozec, L; (2015) Nanoadhesion of Staphylococcus aureus onto Titanium Implant Surfaces. Journal of Dental Research, 94 (8) pp. 1078-1084. 10.1177/0022034515591485.

Downloaded from UCL Discovery: http://discovery.ucl.ac.uk/1469823

\title{
Nanoadhesion of Staphylococcus aureus onto titanium implant surfaces
}

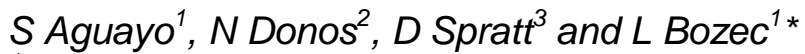 \\ ${ }^{1}$ Department of Biomaterials and Tissue Engineering, UCL Eastman Dental Institute, University \\ College London, London, UK \\ ${ }^{2}$ Periodontology Unit, UCL Eastman Dental Institute, University College London, London, UK \\ ${ }^{3}$ Division of Microbial Diseases, UCL Eastman Dental Institute, University College London, \\ London, UK \\ * Corresponding author: Division of Biomaterials and Tissue Engineering, UCL Eastman Dental \\ Institute, University College London, 256 Gray's Inn Road, London, WC1X 8LD, UK; E: \\ Sebastian.aguayo.13@ucl.ac.uk
}

\begin{abstract}
Adhesion of bacteria to dental implant surfaces is the critical initial step in the process of biofilm colonisation, however, the specific nanoadhesive interactions occurring during the first contact between bacterial cells and biomaterial substrates remains poorly understood. In this report, we utilise single-cell force spectroscopy (SCFS) to characterise the dynamics of the initial interaction between living Staphylococcus aureus cells and machined titanium (Ti) surfaces at the nanoscale. Values for maximum adhesion force were found to increase from 0s ($0.27 \pm 0.30 \mathrm{nN})$ to $60 \mathrm{~s}(-9.15 \pm 0.78 \mathrm{nN})$ surface delays, with similar results observed for total adhesion work (7.39 \pm 2.38 and $988.06 \pm 117.08 \mathrm{aJ}$ respectively). Single-unbinding events observed at higher surface delays were modelled according to the worm-like chain (WLC) model, obtaining molecular contour-length predictions of $314.06 \pm 9.27 \mathrm{~nm}$. Average single-bond rupture forces of $-0.95 \pm 0.04 \mathrm{nN}$ were observed at increased contact times. Short-range $\left(F_{\mathrm{SR}}\right)$ and long-range-force $\left(F_{\mathrm{LR}}\right)$ components of bacterial adhesion were obtained by Poisson analysis of single-unbinding event peaks, yielding values of $-0.75 \pm 0.04 \mathrm{nN}$ and $-0.58 \pm 0.15 \mathrm{nN}$ respectively. Addition of $2 \mathrm{mg} / \mathrm{ml}$ chlorhexidine $(\mathrm{CHX})$ to the buffer solution resulted in the inhibition of specific adhesive events but an increased overall adhesion force and work. These results suggest that initial attachment of $S$. aureus to smooth $\mathrm{Ti}$ is mostly mediated by shortrange attractive forces observed at higher surface delays.
\end{abstract}

Keywords: atomic force microscopy, biophysics, nanomechanics, microbiology, dental implants

\section{Introduction}

Biofilm formation on artificial prosthetic elements remains a major problem in the biomedical field (Esposito et al. 2007). Thus, many efforts are currently being placed in understanding the biophysical events influencing bacterial adhesion and colonisation of implanted devices. In oral medicine, it is widely accepted that the placement of dental implants is an efficacious treatment considering the high survival rates shown in clinical trials over the years (Setzer and Kim. 2014). The introduction of osseointegrated implants was a major breakthrough for dentistry, and ever 
since, it has provided clinicians with predictable long-term outcome treatments for the replacement of single/multiple missing teeth (Esposito et al. 1998). Despite the fact that titanium (Ti) implants are regarded as gold standard, surface infection remains a frequent complication that increases failure rates and patient morbidity (Zhao et al. 2014). The development of biofilms on implants involves a series of stages, starting with adhesion of early-colonising bacteria and followed by the subsequent binding of secondary colonisers (Otto. 2013).

Staphylococcus aureus is a well-known Gram-positive pathogen involved in a vast number of human infections (Roberts et al. 2006). The presence of microbial surface components recognising adhesive matrix molecules, MSCRAMMs, on the membrane of $S$. aureus is a key factor for recognition and adhesion to surfaces (Buck et al. 2010). It has been shown that $S$. aureus has an increased affinity to $\mathrm{Ti}$ substrates, being found consistently adhered to the surface of implants (Izquierdo-Barba et al. 2015). Interestingly, S. aureus is frequently isolated from failing dental implant sites and associated to poor clinical outcomes (Lee and Wang. 2010).

Biophysically, the attachment of bacteria to surfaces can be regarded as a two-step process: an initial cell-surface interaction dominated mostly by non-specific forces, followed by secondary short-range interactions mediated by specific bonding between the bacterium and substrate (Chen et al. 2014). In this stage, irreversible cell-surface coupling occurs and removal of the bacterium is only possible by mechanical or chemical action. Many authors have recently utilised atomic force microscopy (AFM) as a tool for probing the nanoadhesion of bacteria to substrates, where adhesive interactions between the cell and surface can be characterised with nano-newton sensitivity (Aguayo et al. 2015). By using this single-cell force-spectroscopy (SCFS) technique, information regarding adhesion force and overall adhesion work has been obtained for living bacteria (Beaussart et al. 2013). Furthermore, adhesion force can be decoupled into short-range $\left(F_{\mathrm{SR}}\right)$ and long-range-force $\left(F_{\mathrm{LR}}\right)$ components by applying Poisson statistical analysis (Gordesli and Abu-Lail. 2012). This approach has been reported extensively in the literature for different strains of bacteria (Abu-Lail and Camesano. 2006; Mei et al. 2009a; Mei et al. 2009b). Using SCFS, it is also possible to measure the elastic properties of polypeptides, as the analysis of force-extension data yields information on the total molecular length of a given protein (Buck et al. 2010; Chan et al. 2010).

In this study we present our findings regarding nanoadhesion between $S$. aureus and smooth $\mathrm{Ti}$ surfaces, and suggest an approach for evaluating the adhesion of bacteria to implant surfaces centred on the analysis of single unbinding peaks observed at increased surface delays.

\section{Experimental}

\subsection{Titanium substrates}

Sterile $15 \mathrm{~mm}$-diameter smooth Ti discs provided by Straumann (Basel, Switzerland) were employed. To evaluate surface morphology of Ti discs, a Philips XL30 FEG-SEM scanning electron microscope was employed with an acceleration voltage of $5 \mathrm{kV}$, and AFM characterisation (NanoWizard II, JPK Instruments, Germany) was performed in contact mode employing NP-S10 probes (Bruker, Santa Barbara, USA) with a spring constant of $0.3 \mathrm{~N} / \mathrm{m}$ at a scanning rate of $1.0 \mathrm{~Hz}$. Topography was measured by profilometry (Scantron, Proscan 1000, UK) obtaining $R_{a}$ values for surface roughness, and surface wettability was calculated employing $\mathrm{dH}_{2} \mathrm{O}$ droplets on an optical contact angle meter (KSV Instruments, CAM 200, USA).

\subsection{Bacterial cultures}

Cultures of Straphylococcus aureus (8325-4) were grown in TSB broth (Oxoid Ltd, UK) for 16hr at $37^{\circ} \mathrm{C}$ and aeration. For AFM experiments, a 20 -fold dilution of cells in stationary phase was obtained by centrifugation for $1 \mathrm{~min}$ at 5000rpm (Eppendorf 5417R, UK), washed three times 
and resuspended in TRIS-buffer (pH7.4, Sigma-Aldrich, UK). A 50ul aliquot of resulting bacterial dilution was transferred to a sterile glass slide for cell probe preparation.

\subsection{AFM imaging of live Gram-positive bacteria}

A $100 \mu \mathrm{l}$ droplet of gelatin (Sigma-Aldrich), poly-L-lysine (PLL) (P4707, Sigma-Aldrich) or a solution of $4 \mathrm{mg} / \mathrm{ml}$ dopamine hydrochloride in 10mM TRIS buffer, pH8.0 (poly-DOPA) (Dopamine Hydrochloride, Sigma-Aldrich) was placed on the surface of a sterile glass slide (Select Micro Slides, Solmedia; 20min sterilisation cycle, BR-506, UVC Light Products, UK). After a 1-hour incubation period, surfaces were rinsed 3 times with $\mathrm{dH}_{2} \mathrm{O}$ and dried under $\mathrm{N}_{2}$ airflow.

For imaging, cells were harvested by centrifugation at 5000rpm during $1 \mathrm{~min}$, washed three times and re-suspended into $1 \mathrm{ml}$ of $\mathrm{dH}_{2} \mathrm{O}$. Finally, a $50 \mu \mathrm{l}$ droplet of 10 -fold diluted bacterial suspension was incubated for $15 \mathrm{~min}$ on each pre-treated surface, and unattached cells were removed gently with $\mathrm{dH}_{2} \mathrm{O}$. Resulting bacteria-coated glass cover slips were imaged in PBS or $\mathrm{dH}_{2} \mathrm{O}$ by employing a JPK NanoWizard II AFM system mounted on an Olympus IX71 (Olympus, Japan) inverted microscope, in intermittent-contact mode. MSNL-10 cantilevers (Bruker, Santa Barbara, USA) tuned to a drive frequency of $\sim 46 \mathrm{kHz}$ (nominal resonant frequency $25-50 \mathrm{kHz}$ ) were employed with a constant line rate of $0.3 \mathrm{~Hz}$. Gain parameters and setpoint were adjusted according to each sample, and thermal resonance calibration yielded spring constants of $\sim 0.11 \mathrm{~N} / \mathrm{m}$.

\subsection{Functionalisation of cell probes}

Construction of functionalised colloidal probes was performed by attaching $\sim 10 \mu \mathrm{m}$ diameter glass microspheres (Whitehouse Scientific, UK) to NP-O10 tip-less cantilevers (Bruker, Santa Barbara, USA) by employing a thin layer of UV-curable glue (Loctite, UK). Optical microscope and SEM confirmed adequate attachment of a single microsphere on each cantilever. Thermal calibration yielded spring constant values of $\sim 0.3 \mathrm{~N} / \mathrm{m}$. Subsequently, colloidal probes were coated with a poly-DOPA solution for $1 \mathrm{hr}$, rinsed and dried under $\mathrm{N}_{2}$. Probes were then placed into contact with isolated bacterial cells for $\sim 3 \mathrm{~min}$ until attachment was observed, and subsequently positioned over the titanium substrate for force measurements.

\subsection{SCFS force measurements}

All SCFS measurements were carried out in TRIS-buffer at room temperature immediately after cell probe construction. To minimise the influence of surface topography, multiple force curves were recorded for each cell probe at representative areas of the sample. Measurements were performed with increasing dwelling times of 0,1,15, 30 and 60s; with a loading force of 500pN and a constant speed of $2.0 \mu \mathrm{m} / \mathrm{sec}$. Optimal loading force was determined by applying increasing loading forces to immobilised $S$. aureus cells with a MSNL-10 cantilever until indentation was observed. Control force-curves for both glass microspheres and DOPA were also obtained. A minimum of three probes from independent bacterial cultures were employed.

As a model to inhibit specific adhesion, $2 \mathrm{mg} / \mathrm{ml}$ concentration of chlorhexidine (CHX) (Sigma, UK) was added to the buffer solution, the probe for $5 \mathrm{~min}$ before force-curves were recorded. Force-curves with a 60 s dwelling time were obtained using three independent probes.

\subsection{Bacteria and cell-probe viability experiments}

To assess viability of bacterial cells throughout measurements, a bacterial live/dead stain was employed (Live/Dead Baclight, Life Technologies, USA). Briefly, $1.5 \mu \mathrm{l}$ of SYTO9 nucleic acid stain was mixed with $1.5 \mu \mathrm{l}$ of propidium iodide and added to prepared bacterial suspensions. Viability was confirmed by green fluorescence of bacteria upon attachment and throughout 
measurements, whereas red fluorescence was used as an indicator of bacterial death. Bacterial suspension in isopropanol was used as a negative control.

\subsection{Data extraction and statistical analysis}

Maximum adhesion force and adhesion work values were collected from resulting force-curves (Francius et al. 2009) and expressed as mean \pm SE, and further analysed with the Kruskall-Wallis test for non-parametric variables considering significance at $p<0.05$. Data from increased dwelling times (60s) was modelled according to the worm-like chain (WLC) model previously described (Storm and Nelson. 2003) to yield predicted contour length values for individual peaks. Five independent probes were employed for WLC modelling. Each minor detachment peak observed after the maximum adhesion event was fitted to the WLC model, given by the equation

$$
\mathrm{F}(\mathrm{x})=\frac{\mathrm{k}_{\mathrm{b}} T}{1_{\mathrm{p}}}\left[\frac{1}{4}\left(1-\frac{x}{L}\right)^{-2}+\frac{x}{L}-\frac{1}{4}\right]
$$

, where $F$ is force $(\mathrm{N}), k_{b}$ is the Boltzmann constant $(\mathrm{J} /$ kelvin), $T$ is temperature (kelvin) and $x$ is molecular extension $(\mathrm{m})$. Persistence length, $I_{p}$, was assumed to be $0.36 \mathrm{~nm}$ (approximate length of a single amino-acid), thus obtaining values for molecular contour length (L). Decoupling of bacterial adhesion forces was obtained by Poisson analysis by employing a previously reported approach (Chen et al. 2011) yielding both short-range $\left(F_{\mathrm{SR}}\right)$ and long-range-force $\left(F_{\mathrm{LR}}\right)$ components for bacterial adhesion.

\section{Results and discussion}

3.1. Immobilisation of living $S$. aureus cells for AFM imaging and nanomechanics

The effectiveness of three immobilisation agents was initially assessed for AFM imaging and SCFS of live $S$. aureus cells. Both gelatin and PLL coated surfaces were found to be ineffective for the immobilisation of bacteria to surfaces in buffer solution, as cells became rapidly detached during scanning. Poly-DOPA was found to be the only substance to effectively immobilise $S$. aureus cells for AFM imaging under buffered conditions (Figure 1.a and 1.b). Cell morphology and aggregation of $S$. aureus immobilised to poly-DOPA was consistent with SEM imaging, and Live/Dead staining confirmed viability for well over 90 mins when attached to poly-DOPA coated substrates (data not shown). Doktycz et al. were also unable to image bacteria attached to PLL surfaces. These authors, however, were able to image $S$. aureus on gelatin-coated surfaces, although they reported several difficulties to obtain effective immobilisation in minimal media buffer environment (Doktycz et al. 2003).

Overall, $\mathrm{dH}_{2} \mathrm{O}$ allowed for much straightforward imaging when compared to PBS. This can be explained mostly by the strong ionic charge of this particular buffer, as immobilisation of cells onto gelatin, PLL and poly-DOPA is strongly dependent on the effective interaction between the negative-charged bacterial wall and the positive-charged surface created (Louise Meyer et al. 2010; Webb et al. 2011). Altogether, poly-DOPA proved to be an effective and non-invasive approach for immobilisation of $S$. aureus to surfaces.

\subsection{S. aureus cell-probe fabrication}

Cell-probe construction was possible by employing the Nanowizard as a micromanipulator, initially attaching a glass microsphere to a tipless cantilever and subsequently immobilising bacteria by means of poly-DOPA coating. SEM imaging confirmed the success of the protocol for immobilising a reduced amount of bacteria on the microsphere (Figure 1.c). Similar approaches have been recently described in which both Gram-positive and Gram-negative 
bacteria have been effectively immobilised to colloid cantilevers (Beaussart et al. 2013; Sullan et al. 2014).

In nature, bacterial adhesion occurs by the initial positioning of a bacterium to the close vicinity of a surface, which is mainly governed by physical interactions. Therefore, to effectively represent the physiological conditions leading towards bacterial adhesion to surfaces, the maximum loading force without excessively compressing the cell was determined. To do so, $S$. aureus cells immobilised on poly-DOPA coated glass were indented until deformation was recorded, yielding an optimal loading force of $500 \mathrm{pN}$. By employing this force, minimal mechanical deformation was exerted on the bacterial surface during experiments.

Finally, Live/Dead fluorescent staining demonstrated that constructed cell probes remained viable for over 60 minutes when probed against the Ti substrate with a $500 \mathrm{pN}$ loading force (data not shown). Therefore, all measurements were carried out within an hour from probe preparation. Live/Dead stained cells were not employed for SCFS as the effect of staining on bacterial mechanical properties is unknown.

\subsection{Deciphering the Staphylococcus aureus-Ti nanoadhesive interaction}

Mean adhesion forces and adhesion work values between $S$. aureus and smooth Ti are shown in Figure 2. Maximum adhesion forces for $S$. aureus were found to increase from 0 s to 60 s surface delays $(-0.27 \pm 0.3 \mathrm{nN}$ and $-9.15 \pm 0.78 \mathrm{nN}$, respectively), with similar results observed for total adhesion work $(7.39 \pm 2.38$ and $988.06 \pm 117.08$ aJ, respectively). We found, however, that reduced surface delays ( 0 s and $1 \mathrm{~s}$ ) showed no significant difference in adhesion force between the poly-DOPA coating and bacterial probes, as differences only became apparent at increased surface delays. Utilising similar approaches, Mei et al observed similar effects for nine different strains of oral Gram-positive bacteria when increasing surface delays from 0 to 120 s (Mei et al. 2009a). Furthermore, retraction curve patterns and force values at 1 s surface delays ($1.48 \pm 0.08 \mathrm{nN}$ ) are consistent with previous reports in literature for $S$. aureus and other Grampositive strains (Herman et al. 2013).

Force curves obtained at increased contact times $(>1 \mathrm{~s})$ showed characteristic unbinding patterns described previously in literature as 'jumps' and/or 'tethers' which describe the unbinding of single adhesive units (Taubenberger et al. 2013) (Figure 2.a). These singleunbinding events are observed to the right of the major adhesion peak at $Z$ distances usually over $>150 \mathrm{~nm}$. At increased surface contact, two main variations of unbinding patterns were found repeated throughout SCFS measurements. For about $50 \%$ of resulting force curves, $5-8$ consecutive detachment peaks were observed at regular intervals, whereas in remaining force curves unbinding events seemed to follow a more irregular pattern (Figure 3.b). Regardless, no significant differences in rupture force or predicted contour length values were found between the two scenarios, and therefore it is believed that these differences reflect the dynamic nature of the interaction of $S$. aureus with Ti surfaces.

In the present report, unbinding-events were observed in $8-10 \%$ of force-curves at 1 s contact time; however, surface delays of 60 s increased this occurrence to $91 \%$, which is consistent with time-dependent binding mediated by surface proteins. Similarly to our approach, Yongsunthon and Lower observed sawtooth-like unbinding events in 2-3\% of recorded force-curves between $S$. aureus and silica and polystyrene beads in buffer at $\sim 1$ s surface delays, which they attributed to protein-mediated binding (Yongsunthon and Lower. 2006).

Average rupture force for single-unbinding events between cell probes and Ti surfaces at 60s contact time was found to be $-0.95 \pm 0.04 \mathrm{nN}$, which is similar to previous reports in literature. Liu 
et al. reported rupture values of $\sim-1 \mathrm{nN}$ between Staphylococus epidermidis probes and a coated fibrinogen (Fg) substrate (Liu et al. 2008), and Boks et al. found average rupture values for four staphylococcal strains probed against a glass substrate at $\sim 1.05 \mathrm{nN}$ (Boks et al. 2008). Furthermore, it was possible to model single-unbinding events according to the worm-like chain (WLC) model, obtaining molecular contour-length predictions of $314.06 \pm 9.27 \mathrm{~nm}(\mathrm{n}=319)$ (Figure 3.a). The contour length given by the WLC model represents the total length of a completely unfolded molecule or protein (Chan et al. 2010). The value of $\sim 314 \mathrm{~nm}$ we obtained from WLC modelling is in the range of several important $S$. aureus surface-anchored adhesins which have been extensively described in literature (O'Neill et al. 2008). By considering the length of a single amino acid to be $\sim 0.36 \mathrm{~nm}$ (Herman et al. 2014) we can obtain the contour length for important $S$. aureus adhesins such as protein $A(\sim 183 \mathrm{~nm})$ (Uhlen et al. 1984), clumping factor ClfA ( 336nm) (Hartford et al. 1997), fibrinogen-binding proteins FnBPA and FnBPB ( 366nm) (Keane et al. 2007) and cna ( 426nm) (Patti et al. 1992). Interestingly, FnBPA has been shown to express strongly in $S$. aureus 8325-4, the strain of choice in the present study. Although WLC modelling is not regularly applied to SCFS, many studies do report the maximum rupture length between the cell probe and substrate, with values of $50-600 \mathrm{~nm}$ for adhesin-Fg complexes (Herman et al. 2014), >200nm for bacterial pairs (Younes et al. 2012), and 400-600nm between oral streptococci and stainless steel surfaces (Mei et al. 2009b). Therefore, it is believed that contour lengths obtained with the WLC model, with most values in the $200-400 \mathrm{~nm}$ range, are a result of receptor-surface interactions between living $S$. aureus cells and Ti substrates. To the best of our knowledge, this is one of the initial attempts to predict the contour length of bacterial adhesive proteins from SCFS measurements with the WLC model.

Additionally, Poisson analysis of adhesion forces was used to divide minor adhesion peaks into $F_{\mathrm{SR}}$ and $F_{\mathrm{LR}}$ components as described previously in literature (Chen et al. 2011) (Figure 4). Fiveindependent $S$. aureus probes were utilised, yielding $F_{\mathrm{SR}}$ values of $-0.75 \pm 0.04 \mathrm{nN}$ and $F_{\mathrm{LR}}$ of $0.58 \pm 0.15 \mathrm{nN}$ respectively. Both short and long-range-forces we found to be attractive in nature, which may help explain the affinity observed between $S$. aureus and Ti surfaces. Similar values were reviewed by Chen et al. for several Gram-positive strains (Chen et al. 2011), and Boks et al. reported average values of $-0.7 \mathrm{nN}$ contribution for short-range interactions between $S$. epidermidis and glass surfaces (Boks et al. 2008). $F_{S R}$ can be considered to reflect the value of hydrogen bonding between the bacterial cell and surface. Ti surfaces employed in this study were slightly hydrophilic in nature, with $R_{a}$ and contact angle values of $0.61 \mu \mathrm{m}$ and $67.0 \pm 5^{\circ}$, respectively, which correspond with previous literature (Logan et al. 2015). Bacteria have higher tendencies to form hydrogen bonds with hydrophilic surfaces, which have also been shown to strengthen at prolonged contact times. Abu-lail and Camesano reported rupture forces for individual hydrogen bonds at around $-0.13 \mathrm{nN}$ (Abu-Lail and Camesano. 2006), and therefore it is possible to hypothesise that several hydrogen bond bridges are involved in a single $S$. aureus-Ti adhesive unit.

\subsection{Inhibition of single-unbinding events by $2 \mathrm{mg} / \mathrm{ml}$ chlorhexidine}

To test the idea that bond-strengthening observed at increased contact times is the result of a dynamic interaction between viable bacterial cells and the substrate, the buffer was replaced with a solution of $2 \mathrm{mg} / \mathrm{ml}$ chlorhexidine (CHX) in TRIS. CHX is a widely used oral antiseptic with demonstrated effectiveness against Gram-positive bacteria (Valderrama and Wilson. 2013). This resulted in the inhibition of specific adhesive events between the bacterial probe and $\mathrm{Ti}$ surfaces (Figure 5).

Our experiments also showed that $\mathrm{CHX}$ increases both adhesion force $(19.51 \pm 2.48 \mathrm{nN})$ and adhesion work (2850.96 $\pm 670.10 \mathrm{aJ})$ of $S$. aureus at 60 s surface delays ( $p<0.05$, Kruskall-Wallis). Similar observations were made by Kishen et al. who found that nanoadhesion of Enterococcus 
faecalis was increased on dentin surfaces after treatment with a $2 \% \mathrm{CHX}$ solution (Kishen et al. 2008). Increase in S. aureus adhesion to $\mathrm{Ti}$ in the presence of $\mathrm{CHX}$ can be explained by a potential 'bridging' effect between the positively-charged CHX molecule and the negativelycharged substrate and bacterial surfaces. This effect could also be a result of loss of integrity of the bacterial wall due to $\mathrm{CHX}$ accumulation (Gilbert and Moore. 2005). Increased adhesion of $\mathrm{CHX}$-treated bacteria on the implant surface could be indicative of the formation of a "baselayer' in-vivo, which may promote the adhesion of secondary bacterial colonisers.

Finally, it is believed that the correct evaluation of bacterial adhesion onto surfaces must take into account interactions observed at increased surface delays, and most importantly, consider analysis of single-unbinding events as a key factor in understanding the biophysics of bacterial adhesion to biomaterials.

\section{Conclusion}

SCFS has proven to be an effective approach to characterise interactions between living $S$. aureus bacteria and clinically-relevant smooth Ti surfaces. Average adhesion force and work are found to increase at higher contact times, suggesting that the formation of cell-substrate bonds is a time-dependant process. Single-unbinding peaks observed at 60 s surface delays are predominantly mediated by short-range hydrogen forces, and may be the result of direct interactions between $S$. aureus surface proteins and Ti substrates. Inhibition of single-unbinding events by $\mathrm{CHX}$ further supports this idea by suggesting that interactions are mostly mediated by components of the bacterial cell-wall.

\section{Acknowledgements}

Authors of the present study report no conflict of interest, and would kindly like to thank the BecasChile PhD Scholarship Programme for funding this research.

\section{References}

Abu-Lail NI, Camesano TA. 2006. Specific and nonspecific interaction forces between Escherichia coli and silicon nitride, determined by poisson statistical analysis.[Erratum appears in Langmuir. 2008 Apr 15;24(8):4420]. Langmuir 22(17):7296-7301.

Aguayo S, Donos N, Spratt D, Bozec L. 2015. Single-bacterium nanomechanics in biomedicine: unravelling the dynamics of bacterial cells. Nanotechnology 26(6):062001.

Beaussart A, Herman P, El-Kirat-Chatel S, Lipke PN, Kucharikova S, Van Dijck P, Dufrene YF. 2013. Single-cell force spectroscopy of the medically important Staphylococcus epidermidisCandida albicans interaction. Nanoscale 5(22):10894-10900.

Boks NP, Busscher HJ, van der Mei HC, Norde W. 2008. Bond-strengthening in staphylococcal adhesion to hydrophilic and hydrophobic surfaces using atomic force microscopy. Langmuir 24(22):12990-12994.

Buck AW, Fowler VG, Jr., Yongsunthon R, Liu J, DiBartola AC, Que YA, Moreillon P, Lower SK. 2010. Bonds between fibronectin and fibronectin-binding proteins on Staphylococcus aureus and Lactococcus lactis. Langmuir 26(13):10764-10770.

Chan Y, Haverkamp RG, Hill JM. 2010. Force-extension formula for the worm-like chain model from a variational principle. J Theor Biol 262(3):498-504. 
Chen Y, Busscher HJ, van der Mei HC, Norde W. 2011. Statistical analysis of long- and shortrange forces involved in bacterial adhesion to substratum surfaces as measured using atomic force microscopy. Appl Environ Microbiol 77(15):5065-5070.

Chen Y, Harapanahalli AK, Busscher HJ, Norde W, van der Mei HC. 2014. Nanoscale cell wall deformation impacts long-range bacterial adhesion forces on surfaces. Appl Environ Microbiol 80(2):637-643.

Doktycz MJ, Sullivan CJ, Hoyt PR, Pelletier DA, Wu S, Allison DP. 2003. AFM imaging of bacteria in liquid media immobilized on gelatin coated mica surfaces. Ultramicroscopy 97(14):209-216.

Esposito M, Hirsch JM, Lekholm U, Thomsen P. 1998. Biological factors contributing to failures of osseointegrated oral implants. (I). Success criteria and epidemiology. Eur J Oral Sci 106(1):527-551.

Esposito M, Murray-Curtis L, Grusovin MG, Coulthard P, Worthington HV. 2007. Interventions for replacing missing teeth: different types of dental implants. The Cochrane database of systematic reviews 4):CD003815.

Francius G, Alsteens D, Dupres V, Lebeer S, De Keersmaecker S, Vanderleyden J, Gruber HJ, Dufrene YF. 2009. Stretching polysaccharides on live cells using single molecule force spectroscopy. Nat Protoc 4(6):939-946.

Gilbert P, Moore LE. 2005. Cationic antiseptics: diversity of action under a common epithet. J Appl Microbiol 99(4):703-715.

Gordesli FP, Abu-Lail NI. 2012. Combined Poisson and soft-particle DLVO analysis of the specific and nonspecific adhesion forces measured between L. monocytogenes grown at various temperatures and silicon nitride. Environ Sci Technol 46(18):10089-10098.

Hartford O, Francois P, Vaudaux P, Foster TJ. 1997. The dipeptide repeat region of the fibrinogen-binding protein (clumping factor) is required for functional expression of the fibrinogen-binding domain on the Staphylococcus aureus cell surface. Mol Microbiol 25(6):10651076.

Herman P, El-Kirat-Chatel S, Beaussart A, Geoghegan JA, Vanzieleghem T, Foster TJ, Hols P, Mahillon J, Dufrene YF. 2013. Forces driving the attachment of Staphylococcus epidermidis to fibrinogen-coated surfaces. Langmuir 29(42):13018-13022.

Herman P, El-Kirat-Chatel S, Beaussart A, Geoghegan JA, Foster TJ, Dufrene YF. 2014. The binding force of the staphylococcal adhesin SdrG is remarkably strong. Mol Microbiol 93(2):356368.

Izquierdo-Barba I, Garcia-Martin JM, Alvarez R, Palmero A, Esteban J, Perez-Jorge C, Arcos D, Vallet-Regi M. 2015. Nanocolumnar coatings with selective behavior towards osteoblast and Staphylococcus aureus proliferation. Acta Biomater.

Keane FM, Loughman A, Valtulina V, Brennan M, Speziale P, Foster TJ. 2007. Fibrinogen and elastin bind to the same region within the $A$ domain of fibronectin binding protein $A$, an MSCRAMM of Staphylococcus aureus. Mol Microbiol 63(3):711-723. 
Kishen A, Sum CP, Mathew S, Lim CT. 2008. Influence of irrigation regimens on the adherence of Enterococcus faecalis to root canal dentin. J Endod 34(7):850-854.

Lee A, Wang HL. 2010. Biofilm related to dental implants. Implant Dent 19(5):387-393.

Liu Y, Strauss J, Camesano TA. 2008. Adhesion forces between Staphylococcus epidermidis and surfaces bearing self-assembled monolayers in the presence of model proteins. Biomaterials 29(33):4374-4382.

Logan N, Sherif A, Cross AJ, Collins SN, Traynor A, Bozec L, Parkin IP, Brett P. 2015. TiO2 coated CoCrMo: Improving the osteogenic differentiation and adhesion of mesenchymal stem cells in vitro. J Biomed Mater Res A 103(3):1208-1217.

Louise Meyer R, Zhou X, Tang L, Arpanaei A, Kingshott P, Besenbacher F. 2010. Immobilisation of living bacteria for AFM imaging under physiological conditions. Ultramicroscopy 110(11):1349-1357.

Mei L, Ren Y, Busscher HJ, Chen Y, van der Mei HC. 2009a. Poisson analysis of streptococcal bond-strengthening on saliva-coated enamel. J Dent Res 88(9):841-845.

Mei L, van der Mei HC, Ren Y, Norde W, Busscher HJ. 2009b. Poisson analysis of streptococcal bond strengthening on stainless steel with and without a salivary conditioning film. Langmuir 25(11):6227-6231.

O'Neill E, Pozzi C, Houston P, Humphreys H, Robinson DA, Loughman A, Foster TJ, O'Gara JP. 2008. A novel Staphylococcus aureus biofilm phenotype mediated by the fibronectin-binding proteins, FnBPA and FnBPB. J Bacteriol 190(11):3835-3850.

Otto M. 2013. Staphylococcal infections: mechanisms of biofilm maturation and detachment as critical determinants of pathogenicity. Annu Rev Med 64(175-188.

Patti JM, Jonsson H, Guss B, Switalski LM, Wiberg K, Lindberg M, Hook M. 1992. Molecular characterization and expression of a gene encoding a Staphylococcus aureus collagen adhesin. J Biol Chem 267(7):4766-4772.

Roberts C, Anderson KL, Murphy E, Projan SJ, Mounts W, Hurlburt B, Smeltzer M, Overbeek R, Disz T, Dunman PM. 2006. Characterizing the effect of the Staphylococcus aureus virulence factor regulator, SarA, on log-phase mRNA half-lives. J Bacteriol 188(7):2593-2603.

Setzer FC, Kim S. 2014. Comparison of long-term survival of implants and endodontically treated teeth. J Dent Res 93(1):19-26.

Storm C, Nelson PC. 2003. Theory of high-force DNA stretching and overstretching. Phys Rev E Stat Nonlin Soft Matter Phys 67(5 Pt 1):051906.

Sullan RM, Beaussart A, Tripathi P, Derclaye S, El-Kirat-Chatel S, Li JK, Schneider YJ, Vanderleyden J, Lebeer S, Dufrene YF. 2014. Single-cell force spectroscopy of pili-mediated adhesion. Nanoscale 6(2):1134-1143. 
Taubenberger AV, Hutmacher DW, Muller DJ. 2013. Single-Cell Force Spectroscopy, an Emerging Tool to Quantify Cell Adhesion to Biomaterials. Tissue Eng Part B Rev.

Uhlen M, Guss B, Nilsson B, Gatenbeck S, Philipson L, Lindberg M. 1984. Complete sequence of the staphylococcal gene encoding protein A. A gene evolved through multiple duplications. J Biol Chem 259(3):1695-1702.

Valderrama P, Wilson TG, Jr. 2013. Detoxification of implant surfaces affected by peri-implant disease: an overview of surgical methods. International journal of dentistry 2013(740680.

Webb HK, Truong VK, Hasan J, Crawford RJ, Ivanova EP. 2011. Physico-mechanical characterisation of cells using atomic force microscopy - Current research and methodologies. $J$ Microbiol Methods 86(2):131-139.

Yongsunthon R, Lower SK. 2006. Force spectroscopy of bonds that form between a Staphylococcus bacterium and silica or polystyrene substrates. Journal of Electron Spectroscopy and Related Phenomena 150(2-3):228-234.

Younes JA, van der Mei HC, van den Heuvel E, Busscher HJ, Reid G. 2012. Adhesion forces and coaggregation between vaginal staphylococci and lactobacilli. PLoS ONE [Electronic Resource] 7(5):e36917.

Zhao B, van der Mei HC, Subbiahdoss G, de Vries J, Rustema-Abbing M, Kuijer R, Busscher HJ, Ren Y. 2014. Soft tissue integration versus early biofilm formation on different dental implant materials. Dent Mater 30(7):716-727.

\section{Figure Legend}

Figure 1: Effective immobilisation of live Staphylococcus aureus cells with poly-DOPA allows effective high-resolution imaging and functionalised probe construction. (a) Individual $S$. aureus cells can be imaged in great detail, where septum of dividing cells can be observed (arrow). (b) 3D reconstruction from height image of a group of $S$. aureus bacteria (scale $5 \times 5 \mu \mathrm{m}$ ). (c) SEM image of a reduced number of $S$. aureus cells attached to the tip of the DOPA-coated microsphere.

Figure 2: Adhesive interactions between Staphylococcus aureus colloidal probes and a smooth Ti surface observed by AFM. (a) Representative force-curves at increasing surface delays of 0 , $1,15,30$ and 60s. $X$ axis values represent distance in $\mu \mathrm{m}$. (b) Mean adhesion force and (c) adhesion work are shown for poly-DOPA and $S$. aureus probes observed at all studied surface delays. Data represents three bacterial probes obtained in three independent experiments. Note that adhesion increases for bacterial probes as a function of contact time. ${ }^{* *} p<0.05$, KruskallWallis.

Figure 3: Worm-like chain (WLC) modelling of single-rupture events observed between Staphylococcus aureus and smooth Ti surfaces. (a) Predicted contour length of $314 \pm 9.27 \mathrm{~nm}$ was found for the unbinding events observed in 5 independent $S$. aureus cell probes $(n=319)$. Persistence length was considered to be $0.36 \mathrm{~nm}$. (b) Two main unbinding patterns were observed throughout experiments, however, no significant differences were observed in contour length predictions. Insets correspond to diagrammatic representations of WLC modelling. X axis values represent distance in $\mu \mathrm{m}$. 
Figure 4: Poisson analysis of staphylococcal bond-strengthening at 60 s surface delays. (a) Mean adhesion values and variance $\left(\mathrm{nN}^{2}\right)$ of single-unbinding peaks for five independent Staphylococcus aureus cell probes. (b) Histogram of adhesion forces, which represent a Poisson distribution. (c) Plotting of force v/s variance yields a linear fit from which short-range and long-range adhesion components can be determined $\left(R^{2}\right.$ linear $\left.=0.97\right)$.

Figure 5: Addition of $2 \mathrm{mg} / \mathrm{ml}$ chlorhexidine $(\mathrm{CHX})$ to the buffer solution disrupts bacterial adhesion and leads to the disappearance of specific adhesion peaks on the corresponding retraction curves. (a) Adhesion force and (b) adhesion work observed for Staphylococcus aureus in buffer solution and after addition of $2 \mathrm{mg} / \mathrm{ml} \mathrm{CHX}$. Insets illustrate the change in forcecurve patterns for 2 independent $S$. aureus cell probes, where inhibition of 'sawtooth-like' unbinding patterns can be observed. $X$ axis values represent distance in $\mu \mathrm{m}$.

\section{Figures}

Figure 1:

a

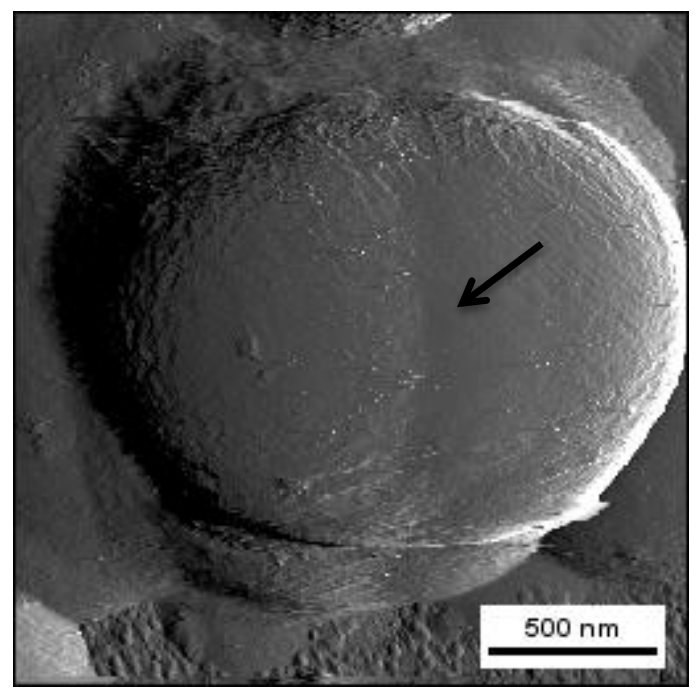

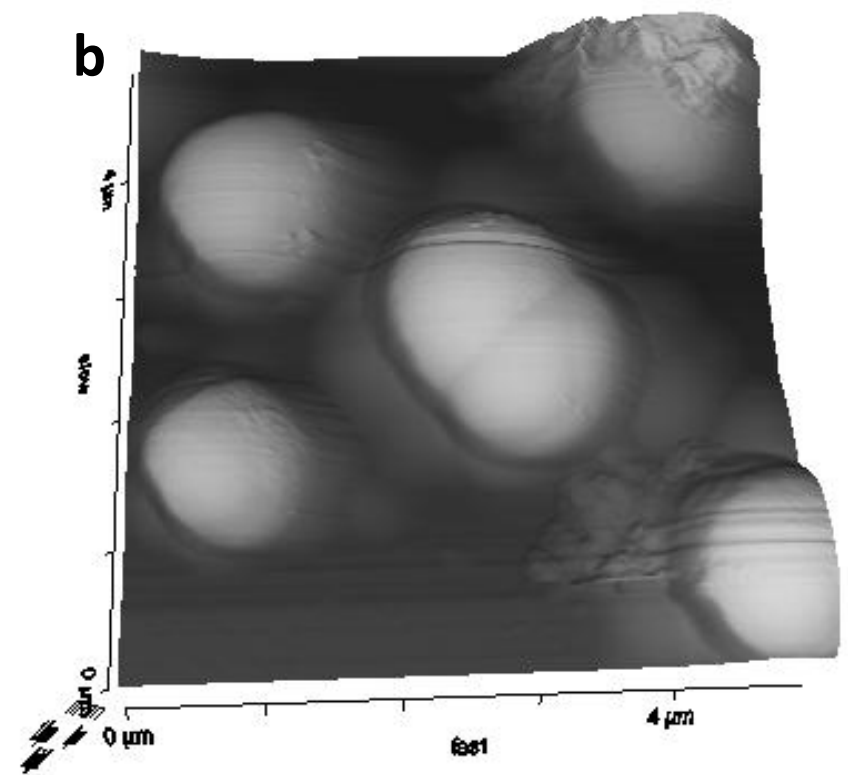

C

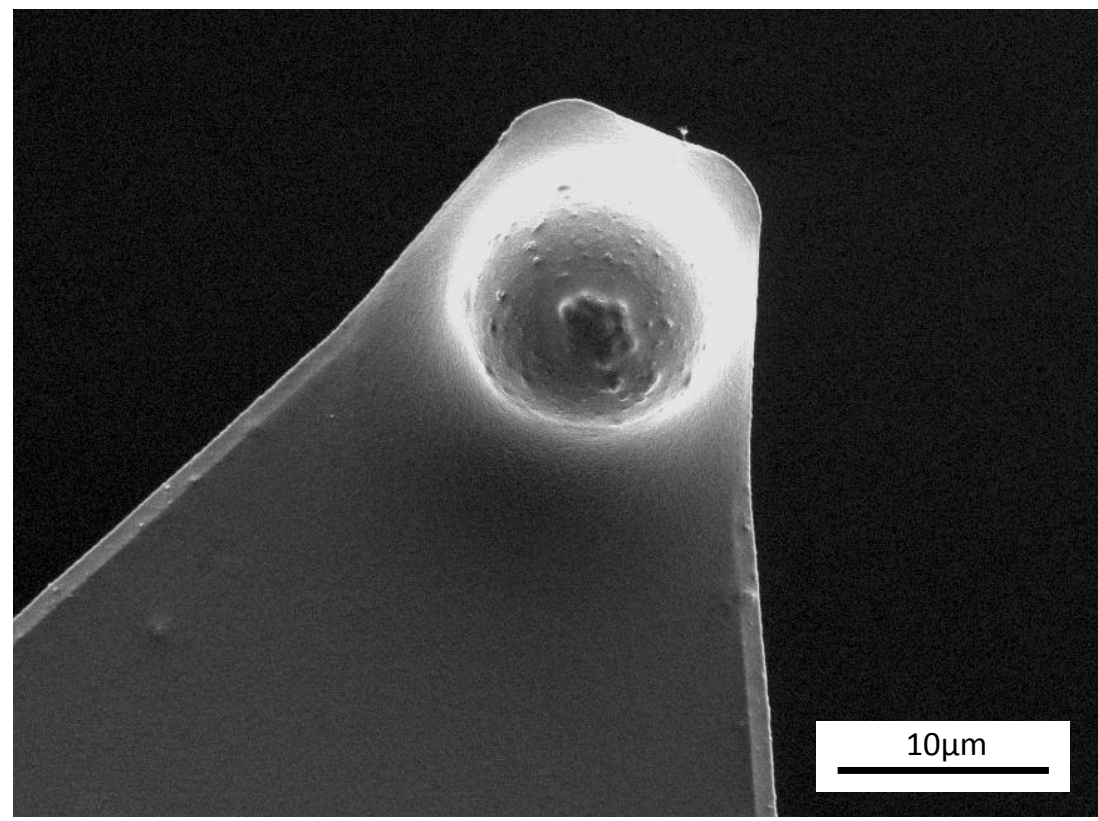


Figure 2:

a

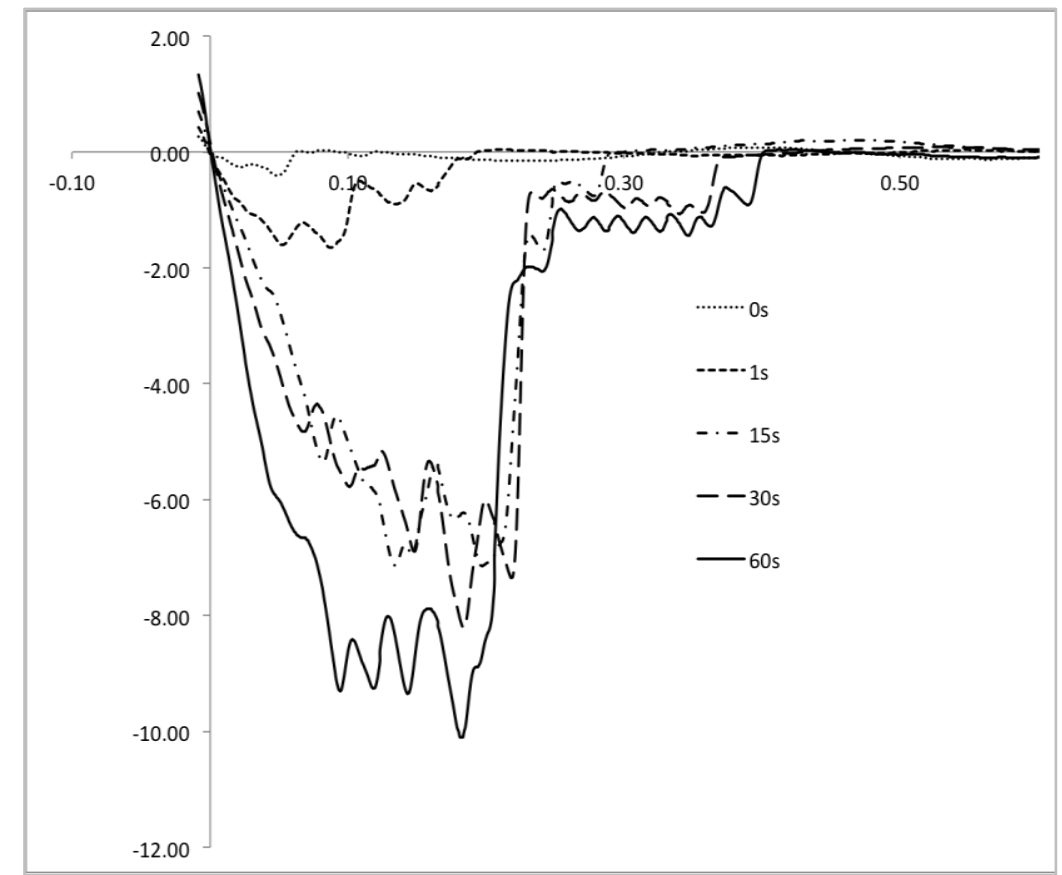

b

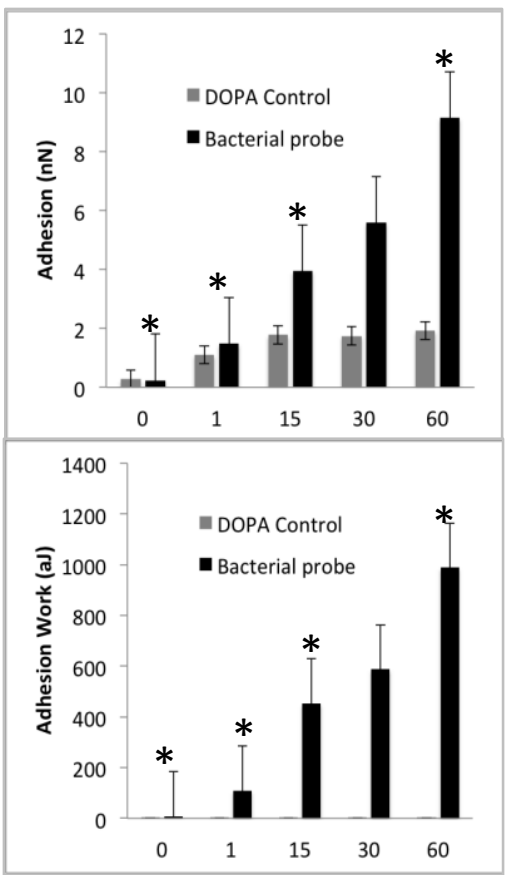

Figure 3:

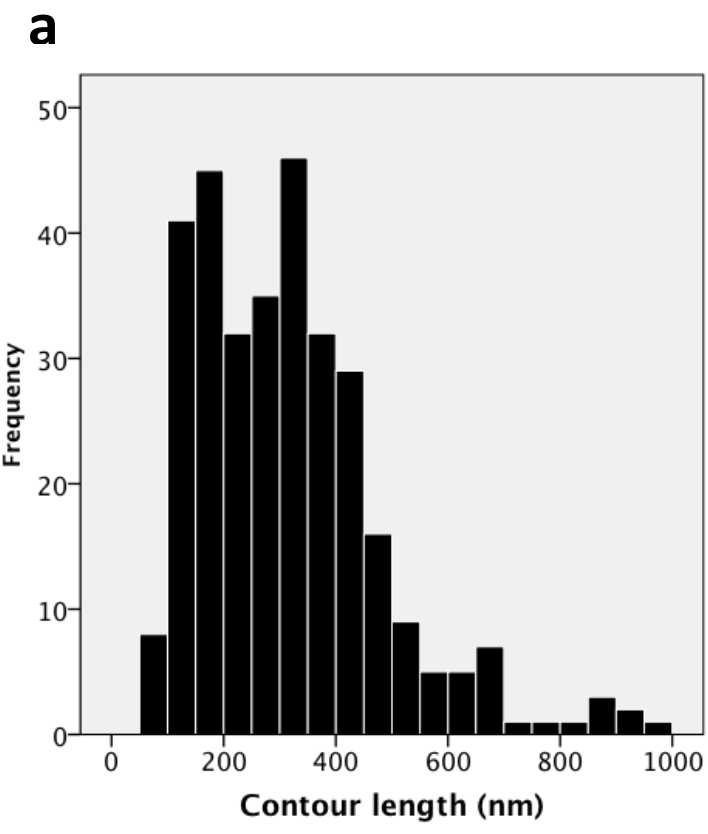

b

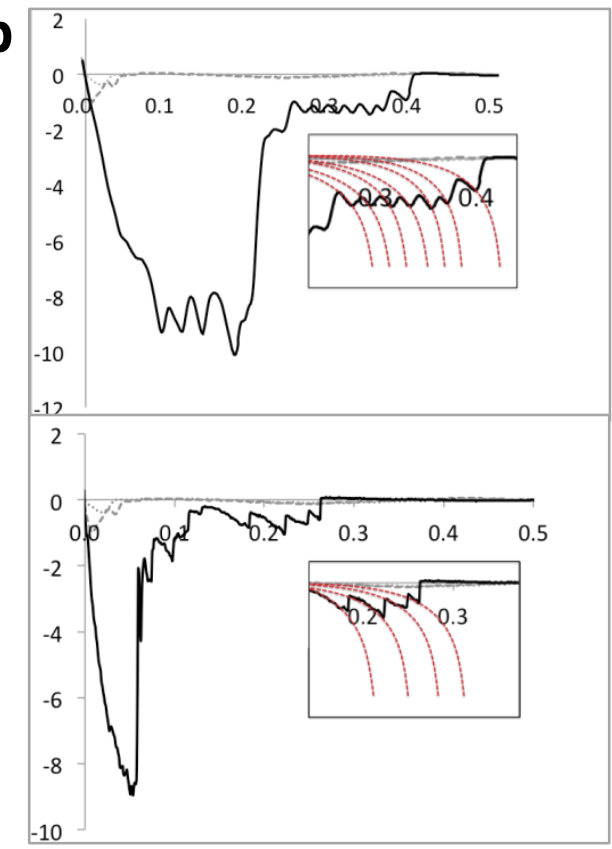


Figure 4:

\begin{tabular}{|rrrrr|}
\hline Probe & & Mean Adhesion $(\mathbf{n N})$ & Variance & \multicolumn{2}{c|}{ Number of peaks } \\
\hline & 1 & -1.72 & 1 & 101 \\
& 2 & -0.82 & 0.22 & 78 \\
& 3 & -0.74 & 0.31 & 43 \\
& 4 & -0.42 & 0.08 & 85 \\
Total & 5 & -0.47 & 0.08 & 46 \\
\hline
\end{tabular}
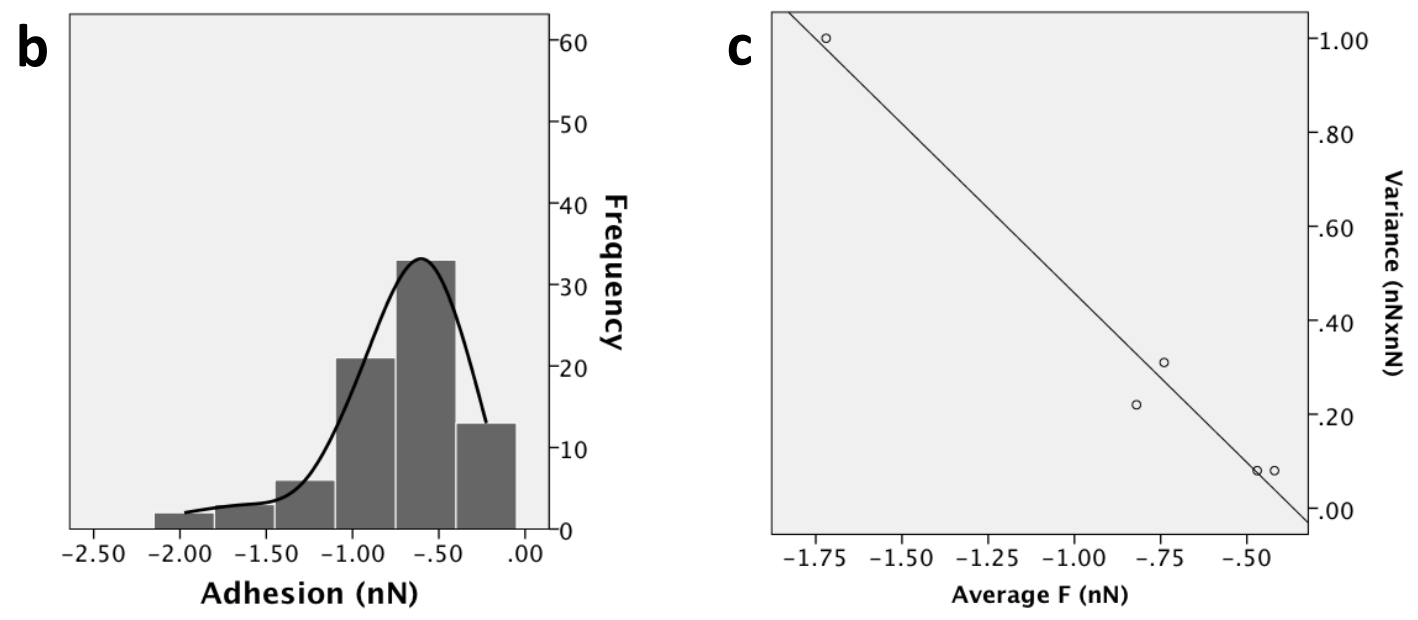

Figure 5:
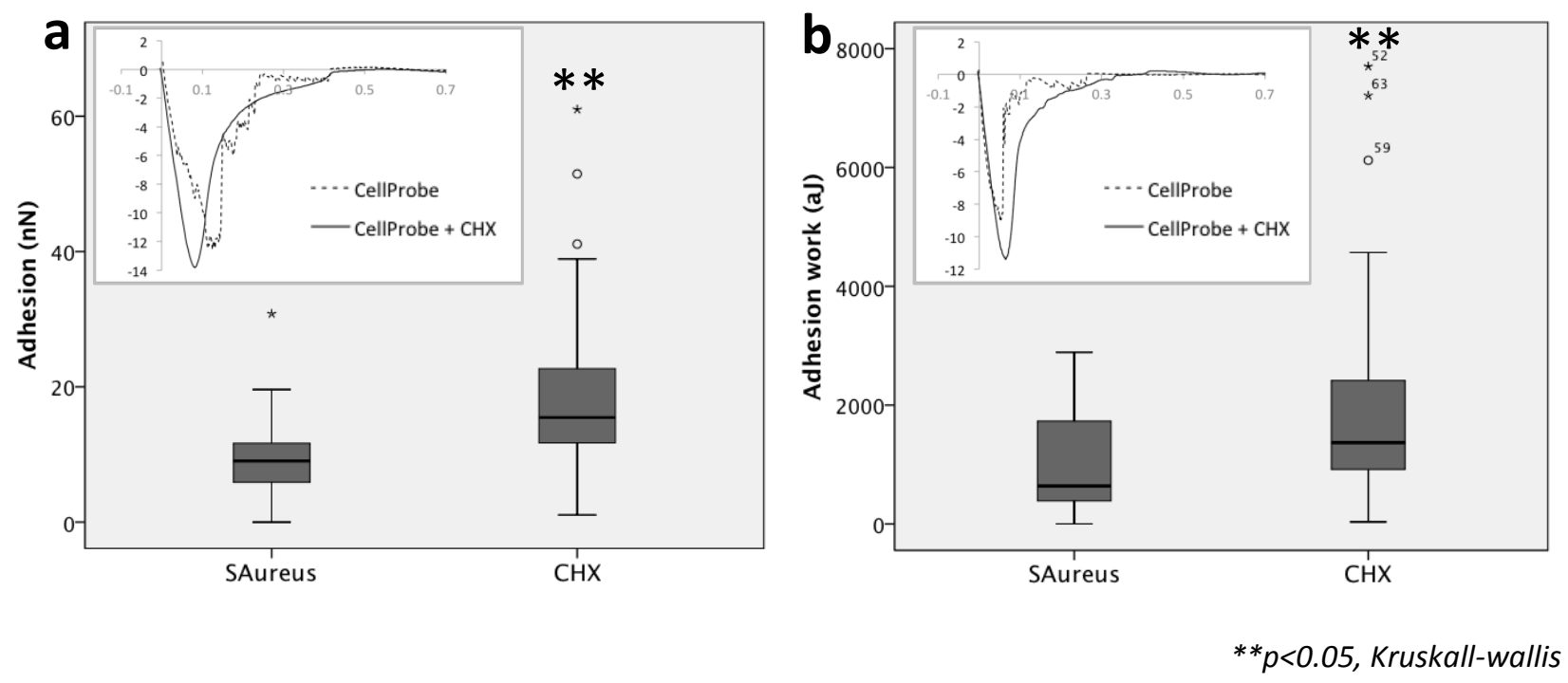